\title{
A FILOSOFIA HERMENÊUTICA DE BACHELARD: DO FILÓSOFO DIANTE DO PROCESSO DO SABER CIENTÍFICO
}

\author{
Jonivan Martins de Sá ${ }^{1}$ \\ Universidade do Vale do Rio dos Sinos (UNISINOS) \\ (D) https://orcid.org/0000-0001-9849-160X
}

\begin{abstract}
RESUMO:
O seguinte trabalho tem por propósito uma breve análise acerca do pensamento do filósofo francês Gaston Bachelard. Para tal, inicialmente, retomarei de forma sucinta a trajetória biográfica deste, recuperando elementos históricos que teriam certa influência em sua construção teórica. Posteriormente, analisarei alguns daqueles que são considerados como conceitos centrais à obra de Bachelard e que buscam dar cabo das discussões a respeito do saber científico e de como este se daria sob o signo de uma ruptura. As análises que apresentarei neste buscarão colocar a obra de Bachelard dentro de uma conjuntura hermenêutica, onde estas rupturas epistemológicas representariam, sobretudo, reestruturação linguística e de sentido.
\end{abstract}

PALAVRAS-CHAVE: Bachelard; Conhecimento; Hermenêutica.

\section{THE BACHELARD'S HERMENEUTICS PHILOSOPHY: FROM THE PHILOSOPHER BEFORE THE SCIENTIFIC KNOWLEDGE PROCESS}

\begin{abstract}
:
This study aims a brief analysis about the thought of the French philosopher Gaston Bachelard. For this purpose, initially, I will return briefly the life histories of this, recovering historical elements that would have some influence in its theoretical construction. Subsequently, I will analyze some
\end{abstract}

\footnotetext{
${ }^{1}$ Mestrando em filosofia pela Universidade do Vale do Rio dos Sinos (UNISINOS), São Leopoldo - Brasil. E-mail: jonivanmartins@yahoo.com.br.
} 
of those who were considered the central concepts to the Bachelard's work, seeking to contribute to the discussions about the scientific knowledge and how this one would take place under the sign of a break. The analysis I present in this, seek to place the work of Bachelard within a hermeneutic conjuncture where these epistemological ruptures represent, above all, linguistic and meaning restructuring.

KEYWORDS: Bachelard; Knowledge; Hermeneutics.

Os horizontes do pensamento de Bachelard se estendem sob um percurso que perpassa as Ciências Naturais (Física, Química, Geometria), a Filosofia e a poesia. Inserida dentro desta conjuntura um tanto disforme, maleável e não-estática, embora de natureza inovadora, encontra-se uma teia complexa de construções teóricas que buscam, justamente, dar conta destas três regiões da epistéme humana. Como não poderia deixar de ser, esta teia reflete nitidamente os percursos transcorridos pelo filósofo durante sua vida. Este licenciou-se em Matemáticas no ano de 1912, lecionando Física e Química em sua cidade natal, Bar-sur-Aube (Condado de Champagne, França). Mais, tarde, inicia oficialmente seus estudos em Filosofia, disciplina que também veio a lecionar. Em 1930 ingressa como professor na Universidade de Dijon. Dez anos mais tarde, passa a lecionar na Sorbonne, em Paris. Sua carreira como professor universitário centra-se em cursos de História e Filosofia das Ciências.

A Teoria da Relatividade de Einstein é apontada muitas vezes como elemento basilar às concepções de Bachelard acerca das ciências e de seus possíveis entrelaçamentos ao pensamento filosófico. "A relatividade não descreve diretamente a realidade, mas organiza o pensamento de modo a levá-lo a se aproximar do real. Postula uma realidade, considerada não como um dado, mas como retificação de ideias, construção racional" (CÉSAR, 1996, p.74). É dentro desta lógica de "retificação de ideias" que nosso filósofo insere-se, fazendo sentir todo o peso de uma época de revoluções científicas e abertura de enunciados filosóficos. Além das teorias de Einstein, cito o eletromagnetismo de Lorentz e a mecânica ondulatória de Louis de Broglie, como fatores positivos na construção desta base científica revolucionária que tanto influenciou Bachelard.

O seguinte trabalho buscará revisitar brevemente - de maneira, talvez, demasiado descritiva - a filosofia das ciências de Bachelard, buscando os elementos de sua estruturação epistemológica e suas sínteses mais expressivas. Para tal, usaremos dois conceitos chave inseridos na obra do autor: o de "ruptura" e o de "novo espírito científico". Dentro desta revisitação - residindo ai a perspectiva crítica do trabalho, seguindo um viés não muito usual na Filosofia das Ciências contemporâneas -, atentarei a uma conjuntura de renovação linguística e de sentido presente nas teorias 
bachelardianas, ou seja, centrarei minhas análises em uma possível conjuntura hermenêutica do trabalho de Bachelard, no sentido de elucidar a sua possível colaboração para a hermenêutica filosófica das ciências.

A exposição da noção de ruptura se torna inevitável ao início de qualquer trabalho que tenha suas bases assentadas nas teorias de Bachelard. A palavra "noção" não é aqui jogada ao acaso. "Noção de ruptura" por não se tratar de um conceito em sentido ortodoxo, mas sim de um transfundo, elemento que permeia todo o pensamento do filósofo. A noção de ruptura é a tese e a síntese do pensamento de Bachelard. Como produto completamente influenciado por sua época, a noção de ruptura propõe uma espécie de caráter diacrônico do conhecimento. O conhecimento científico deixa de ser visto como mera evolução, em sentido linear, pautada pela compreensão do processo como um progresso tranquilo e pacífico. A ruptura do conhecimento em Bachelard ocorre sob o signo da reestruturação. No tocante a uma possível comparação entre a sistematização do pensamento físico de Newton e o de Einstein, por exemplo, Bachelard (1974, p.269) nos mostra que

\begin{abstract}
não se vai do primeiro ao segundo acumulando conhecimento, redobrando o cuidado nas medidas, retificando ligeiramente os princípios. Pelo contrário, é preciso um esforço de novidade total. Segue-se, portanto, uma indução transcendente e não uma indução amplificante, indo do pensamento clássico ao pensamento relativista. Naturalmente, após esta indução, podese, por redução, obter a ciência newtoniana. A astronomia de Newton é, pois, finalmente um caso particular da PanAstronomia de Einstein, como a geometria de Euclides é um caso particular da Pangeometria de Lobatchewski.
\end{abstract}

Portanto, Bachelard percebe a renovação do conhecimento como ruptura estrutural com as antigas percepções; percepções estas que não dão conta de realidades complexas. Como se pode perceber, o antigo nem por isso deixar de existir e de ser elemento constitutivo de uma realidade no conhecimento científico. Ele apenas perde a pretensão de universalidade (BACHELARD, 1974, p.227). Logo, o novo rompe com o antigo, sem necessariamente negálo como um todo, mas sim, completando-o. Dentro desta perspectiva, por exemplo, "[...] o não-cartesianismo é o cartesianismo completado" (BACHELARD, 1974, p.330). Tal forma de ruptura ocorre como processo histórico, mesmo negando uma perspectiva simplista exposta através da noção de progresso, já que

o espírito científico é essencialmente uma retificação do saber, um alargamento dos quadros do conhecimento. Ele julga seu passado histórico, condenando-o. Sua estrutura é a consciência de suas faltas históricas. [...] A essência mesma da reflexão é compreender que não se havia compreendido (BACHELARD, 1974, p.334). 
O processo histórico de ruptura epistemológica inicia com a quebra em relação ao conhecimento primeiro, produto dos sentidos embebidos em certos preconceitos, já que, tal conhecimento primeiro nos leva inevitavelmente ao simplismo, excessiva objetivação dos produtos de nosso conhecimento imediato. Dentro desta perspectiva de quebra, há uma própria reformulação da realidade, pois o sujeito passa a percebê-la sob um novo prisma. Portanto, "o mais real é o mais retificado [...]; não existe conhecimento primitivo que seja conhecimento realista. A realidade máxima está no término do conhecimento e não na origem do conhecimento" (BACHELARD, 2010, p.19). A "coisa" conhecida pela intuição primeira deixa de fazer sentido diante de uma ruptura que leve em conta, por exemplo, os axiomas de boa parte das novas ciências naturais, conhecimento que acaba por abandonar os simplismos das generalizações demasiadas e toma para si o signo da pluralidade estrutural, característica destas novas formas de conhecimento.

A vida comum também nos acostumou a formar nosso conhecimento a partir de um objeto designado, ou seja, um objeto que conserva em toda nossa pesquisa um tipo e uma unidade de existência bem definidos. Mas o cuidado com a extrema precisão, mesmo se parece dirigido a um objeto bem designado, acarreta uma pluralidade essencial de determinação (BACHELARD, 2010, pp.21-22).

A "pluralidade essencial de determinação" é uma das marcas mais acentuadas da filosofia de Bachelard e um forte reflexo das epistemologias científicas que o influenciaram. Tal pluralidade, inevitavelmente torna o processo de conhecer mais minucioso e complexo quando comparado à antigas formas de percepção ${ }^{2}$. Portanto,

[...] na realidade, não há fenômenos simples; o fenômeno é uma trama de relações. Não há natureza simples, substância simples; a substância é uma contextura de atributos. Não há ideia simples, porque uma ideia simples, como viu muito bem Dupréel, deve ser inserida, para ser compreendida, num sistema complexo de pensamentos e de experiências. A aplicação é complicação (BACHELARD, 1974, p.322).

Não se faz de maneira fácil e tranquila a assimilação de tais preceitos de complexidade. $\mathrm{O}$ conhecimento complexo, inevitavelmente exige mais do sujeito conhecedor. As bases simplistas da percepção primeira, não exigem um nível de abstração tão grande quanto as novas percepções, na medida em que não exigem nenhum tipo de ruptura: o sujeito conhece o que vê, sente e ouve e a partir daí desenvolve suas epistémes. O conhecimento

\footnotetext{
${ }^{2}$ Aqui me refiro diretamente a Aristóteles, Euclides e a Descartes. Elucidarei adiante as críticas bachelardianas a tais formas de percepção personificadas nestes nomes.
} 
complexo defendido por Bachelard, que diz respeito ao cuidado minucioso de análise, exige, justamente, este esforço por parte do sujeito: este deve se colocar em uma posição de extremo cuidado não só em relação ao que busca conhecer, mas também no sentido de não se deixar levar por velhas impressões. Dentro desta perspectiva, aqueles que buscam as novas formas de saber, devem inevitavelmente dirigir-se às estruturas mais complexas, para assim, através desse esforço de análise, assimilar um conhecimento mais completo (BACHELARD, 1974, p.235).

A partir da noção de ruptura e da necessidade de formas de percepção mais complexas - de estruturas racionais que deem conta dos novas saberes naturais -, Bachelard sintetiza algumas críticas que já vinham sendo feitas às velhas estruturas de pensamento da tradição científicofilosófica. O que tais críticas propõem, certamente reside no espaço da revolução e caminha lado a lado com as descobertas científicas da segunda metade do XIX em diante.

Bachelard (1974, p.323) fala em um "sistema ternário" que teria estruturado o pensamento filosófico-científico ocidental ${ }^{3}$. Tal sistema é composto pela lógica aristotélica dos silogismos, pela geometria euclidiana, e pela física de Newton, e - salvo os incontáveis avanços técnico-científicos e epistemológicos advindos de tal estrutura racional - parece constituir um dos maiores entraves para as novas concepções científico-filosóficas, se visto sob uma ótica demasiadamente ortodoxa. Dentro desta conjuntura, ocorre um embate que se estende desde o início do século XX entre duas correntes epistemológicas aparentemente bem definidas e que transpassam toda e qualquer forma de saber. Como se pode supor, de um lado há a defesa do velho sistema ternário e de outro aquilo que Bachelard chamou de Novo Espírito Científico (NEC) $)^{4}$, novas concepções lógicas advindas de algumas teorias científicas do século XIX e XX.

Diante disso, proponho uma descrição mais detalhada da crítica bachelardiana de cada um dos preceitos deste antigo sistema ternário que o filósofo do NEC busca não suprimir, mas sim, completar. No sentido de uma discussão um pouco afastada das ciências puramente naturais, aproximando-a de uma conjuntura filosófica, proponho também um breve deslocamento: ao invés de analisar o pensamento newtoniano, irei substituílo pelo pensamento cartesiano - subproduto do primeiro em muitos de seus vieses - que também se encontra inserido dentro da lógica do velho sistema ternário e é larga e diretamente criticado por Bachelard.

\footnotetext{
${ }^{3}$ O termo "ocidental" cunhado aqui, não exclui as vastas críticas construídas acerca da divisão Ocidente/Oriente. Refiro-me por pensamento "ocidental", basicamente, as construções epistemológicas nascidas em berço judaico-cristão, nos países europeus e na América do Norte, a partir da ascensão da cultura grega.

${ }^{4}$ Que analisarei adiante. Optei por uma abreviação - não utilizada por Bachelard - apenas tendo em vista a praticidade.
} 
O fato de Sócrates - provavelmente metade personagem de Platão, metade indivíduo somático - ter instaurado, de certa forma, o uso da razão como o principal norte do exercício filosófico - em detrimento à lógica dos mitos - ainda é visto como o non plus ultra do próprio exercício. A racionalidade, então transmutada em metafísica por Platão, é o início, meio e fim de toda investigação filosófica. Tal racionalidade, de certa forma foi sintetizada por Aristóteles, sobretudo em campo linguístico e de sentido, quando instaurados os elementos de uma lógica ${ }^{5}$. Os silogismos sintetizam tal concepção de racionalidade, ou seja, a própria fórmula sobre a mortalidade de Sócrates - todo o homem é mortal; Sócrates é homem; logo, Sócrates é mortal - pode ser apontada, não sem riscos, como uma de suas maiores contribuições no sentido de sintetização do conhecimento adquirido pela razão.

Em A Filosofia do Não, Bachelard esmiúça aquilo que chamou de uma "lógica não-aristotélica". "Esmiúça", no sentido que buscar uma análise semelhante aos minuciosos estudos de microfísica. Bachelard não inventa o termo "não-aristotélico", nem tão pouco inventa seu sentido, estrutura e crítica. Recupera todos estes elementos - de forma explícita e descritiva - do trabalho de Oliver R. Reiser, intitulado Non-Aristotelian Logic and the Crisis in Science, publicado inicialmente em 1937. Como o próprio termo sugere, Bachelard justapõe esta lógica não-aristotélica à lógica aristotélica, não necessariamente no sentido de contradizê-la, mas de demonstrar os simplismos intrínsecos ao pensamento de Aristóteles. O que o não-aristotelismo propõe é, justamente, completar o aristotelismo: “[...] a lógica não-aristotélica não é incompatível com a lógica aristotélica [...]. A nova lógica é simplesmente mais geral do que a antiga. Tudo o que é correto em lógica restrita permanece naturalmente correto em panlógica. A recíproca é que não é verdadeira" (BACHELARD, 1974, p.227).

Apresento um exemplo utilizado por Reiser, citado e comentado por Bachelard (1974, p.226):

O elétron é um corpúsculo.

O elétron é um fenômeno ondulatório.

Não há dúvida de que assim formuladas, e atribuindo a essas expressões seu significado científico preciso, estas duas definições se excluem mutuamente. Excluem-se porque têm o mesmo sujeito e predicados que se contradizem tão claramente quanto osso e carne, quanto vertebrados e invertebrados. Mas é precisamente a forma demasiado fortemente substantiva, demasiado sumariamente realista, que produz a contradição. O

\footnotetext{
${ }^{5}$ As leituras possíveis de Aristóteles não são poucas, porém os elementos que mais ganham destaque em seu pensamento pela Tradição, no sentido de construção epistemológica, parecem ser os de uma lógica dos silogismos simples. Portanto, a crítica de Bachelard me parece muito mais direcionada à leitura hegemonia que se têm de Aristóteles do que ao próprio. Não pretendo aqui destrinchar as nuances da lógica aristotélica. Os estudos aristotélicos acerca do tema se encontram aglutinados nos livros do Organon.
} 
pensamento realista coloca o sujeito antes dos predicados ao passo que a experiência em microfísica parte de predicados, de predicados longínquos, e esforça-se simplesmente por coordenar as diversas manifestações de um predicado. Obterse-ão fórmulas menos brutalmente opostas convertendo as proposições, dando-lhes a forma um tanto amortecida, própria à lógica não-aristotélica que nunca coloca um sujeito no absoluto. Dir-se-ia, por exemplo:

Em certos casos, a função eletrônica resume-se numa força corpuscular.

Em certos casos, a função eletrônica desenvolve-se numa forma ondulatória.

Tal exemplo, como se percebe, diz respeito à descoberta da mecânica ondulatória - em justaposição à mecânica clássica - de que o elétron, ao analisar-se o fenômeno da propagação da luz, pode se apresentar tanto sob a forma de corpúsculo como sob a forma de onda; mais precisamente, como ambos ${ }^{6}$. Portanto, tendo em vista as experiências advindas das novas ciências, Bachelard defende a validade das teses de Riser, que não anula, como dito, uma lógica de cunho aristotélico, mas sim, propõe uma maior abertura desta, no sentido da compreensão de conjunturas muito mais específicas e complexas do que as analisadas por Aristóteles e pela ciência clássica. A lógica aristotélica dos silogismos dialéticos não dá conta destas conjunturas complexas. O problema que resulta disto é que na

[...] maior parte das vezes os filósofos estão instalados no domínio da lógica aristotélica e é a partir daí que eles pretendem compreender toda a geometria, toda a física. Conseguem-no porque se limitam aos elementos, porque apenas exploram os sistemas em que precisamente o sistema ternário está estabelecido (BACHELARD, 1974, p.232).

Cria-se, então, a partir de algumas das conclusões de Aristóteles, um grande sistema de pensamento vicioso, que - embora tenha contribuído de diferentes e incontáveis formas aos progressos protagonizados pelas civilizações humanas na história - pode atravancar o processo de um conhecimento mais complexo e, até mesmo, aberto.

Como já citei anteriormente, um dos elementos constitutivos do sistema ternário criticado por Bachelard é a geometria euclidiana. As provas

\footnotetext{
${ }^{6}$ Com as palavras do físico e prêmio Nobel Louis de Broglie, um dos mentores da mecânica ondulatória: "Si ahora nos transladamos a las desigualdades de Heisenberg, se vê que los corpúsculos elementares de Física, solo son perfectamente identificables a una onda plana o a un grano localizado, en algunos casos límites muy raros: em general el aspecto 'onda plana' y el aspecto 'grano' existen conjuntamente, pero siendo ambos un poco vagos [...] Se explica entonces por qué la mecánica ondulatoria puede utilizar simultáneamente estas dos concepciones, en aparencia contradictorias [...] es que estas dos imágenes tan diferentes non pueden jamás entrar en contradicción flagrante, toda vez que una de ellas tiende a borrarse cuando la otra se afirma" (1949, pp. 140-141).
} 
da existência de Euclides - que é tido pela Tradição como "o pai da geometria" - são um tanto obscuras. O que nos foi legado foram suas sínteses acerca da noção de espaço. O problema do espaço pode ser visto pueril e preconceituosamente como do domínio das ciências naturais, não da Filosofia, mas em uma análise simplória da obra da grande maioria dos filósofos de tradição ocidental, faz-se sentir todo o peso das noções euclidianas.

A imutabilidade e imobilidade do espaço permeiam o pensamento de Euclides. O espaço estático, dotado de propriedades universais e em repouso, ou seja, o próprio espaço tal qual o percebemos desde há muito tempo, através de noções grosseiras é o objeto das sínteses de Euclides. Este é considerado o pai da geometria, na medida em que racionalizou esta concepção do espaço que advêm da nossa percepção intuitiva/sensorial inicial, primeira. Euclides pode ser considerado como um mero símbolo racional - ou "racionalizador" - das primeiras impressões impensadas sobre o espaço. Assim como a lógica aristotélica, a geometria euclidiana é criticada por Bachelard no decorrer de sua obra como uma espécie de simplificadora de um saber possível, mais complexo do que o primeiro.

A geometria da simplificação de Euclides, como já introduzi, tem um papel fundamental na tradição filosófica. Por exemplo, em Kant, percebe-se a imutabilidade das noções de espaço e tempo, como produto direto da concepção euclidiana (BACHELARD, 2010, p.87). Portanto, com assimilação histórica da racionalização simplista de Euclides acerca do espaço, há o entrelaçamento desta à própria Filosofia ${ }^{7}$. Dado "mais um passo e essa geometria vai surgir como a linguagem fundamental do racionalismo filosófico assim que colocou, como no kantismo, a informação geométrica no mesmo plano a priori" (BACHELARD, 2010, p.73). É como se a intuição geométrica primeira, fosse uma chave de leitura para a própria "realidade" que, por sua vez, se constitui propriamente através desta chave de leitura: a noção geométrica é constituinte das visões de mundo possíveis. E é justamente "[...] pelo aperfeiçoamento da localização que" Bachelard (2010, p.08) "deseja passar do realismo para o realismo esclarecido". Ou usando as palavras de Einstein (1981, p.193),

as percepções dos sentidos apenas oferecem resultados indiretos sobre este mundo exterior ou sobre a "realidade física". Então somente a via especulativa é capaz de nos ajudar a compreender o mundo. Temos então de reconhecer que nossas concepções da realidade jamais apresentam outra coisa a não ser soluções momentâneas.

\footnotetext{
${ }^{7}$ Bachelard (1974, p.258) vai ainda mais longe ao afirmar: "[...] a partir de Euclides e durante dois mil anos, a geometria recebe sem dúvidas acréscimos numerosos, mas o pensamento fundamental permanece o mesmo, e pode-se crer que este pensamento geométrico fundamental é o fundo da razão humana”.
} 
Dentro dos domínios da crítica das novas concepções científicas acerca do tempo e do espaço, há uma espécie de novo despertar dos sujeitos no sentido de uma nova compreensão espacial. É dentro desta conjuntura que nascem as sintetizações de Bachelard e sua crítica filosófica. As descobertas científicas "eram outrora tão raras que se podia falar de razão invariável. Kant, ao escrever após dois mil anos de monótonos progressos efetuados na via única do pensamento euclidiano, podia considerar de modo legítimo, o quadro geométrico como a forma a priori da sensibilidade externa" (BACHELARD 2010, p.87), mas na conjuntura das descobertas da física relativista e da microfísica, tal quadro se mostra insustentável.

Passo agora a uma breve análise do pensamento de Descartes, como uma espécie de representante filosófico - além do já citado Kant - desta racionalidade do antigo sistema epistemológico ternário criticado por Bachelard.

Inegavelmente, o Discurso do Método de Descartes é sua obra mais aclamada pela Tradição Filosófica. Não sem razão, já que parece se tornar base de novas concepções epistemológicas e, sobretudo, coloca o indivíduo diante de uma posição completamente imparcial diante do conhecimento: se outrora se tinha dúvidas sobre "quem", "como" e o "que" se conhecia, com Descartes isso se torna passado, aparentemente.

Quando quis assim pensar que tudo era falso, era preciso necessariamente que eu, que o pensava, fosse alguma coisa. E, observando que esta verdade: penso, logo existo, era tão firme e tão segura que as mais extravagantes suposições dos céticos eram incapazes de abalá-la, julguei que podia admiti-la sem escrúpulo como a primeiro princípio da filosofia que eu buscava. [...] compreendi assim que eu era a substância cuja essência ou natureza consiste apenas em pensar e que, para ser, não tem necessidade nenhuma de lugar nem depende de coisa material alguma. De modo que esse eu, isto é, a alma pela qual sou o que sou, é inteiramente distinta do corpo, sendo inclusive mais fácil de conhecê-la do que ele, e, ainda que ele não existisse, ela não deixaria de ser tudo o que é (DESCARTES, 2005, p.70).

Ou seja, a existência do sujeito é a prerrogativa para o exercício de um conhecimento possível. Naturalmente, não há conhecimento sem existência, mas, sobretudo, não há efetiva evidência da existência, sem pensamento. Pensamento e sujeito estão ligados de maneira ontológica, logo, parece possível uma construção epistemológica pura, no sentido de existir "apenas uma verdade em cada coisa" (DESCARTES, 2005, p.57).

$\mathrm{O}$ método cartesiano - que o guia, inclusive, à afirmação antes destacada - é o próprio método usado pelo homem moderno, que busca o conhecimento sob esta perspectiva ativa, porém imparcial. Em sentido elucidativo, cito os quatro elementos do método cartesiano: 
Primeiro, era não aceitar jamais alguma coisa como verdadeira que eu não conhecesse como tal [...]

$\mathrm{O}$ segundo, dividir cada uma das dificuldades que eu examinasse em tantas parcelas possíveis e que fossem necessárias para melhor resolvê-las [...]

$\mathrm{O}$ terceiro, conduzir por ordem meus pensamentos, começando pelos objetos mais simples mais fáceis de conhecer, para subir aos poucos, como por degraus, até o conhecimento dos mais compostos, e supondo mesmo uma ordem entre os que não se precedem naturalmente $[\ldots]$

E o último, fazer em toda a parte enumerações tão completas, e revisões tão gerais, que eu tivesse a certeza de nada omitir (DESCARTES, 2005, pp.54-55).

Método simples, lógico e direto, através do qual Descartes buscaria incansavelmente um conhecimento possível do universo e seus objetos. Para fins de análise, proponho uma leitura típica de Bachelard do terceiro elemento do método de Descartes.

No terceiro elemento de seu método, Descartes propõe a condução progressiva de sua racionalidade desde os "objetos mais simples" até os "mais compostos". Talvez nesta sua concepção de "objeto" é onde melhor se pode perceber a carga de uma localização espacial euclidiana/newtoniana, assim como do preceito de identidade tão caro a Aristóteles:

- O conhecedor do objeto não parece traçar uma relação com o mesmo, assim como os corpos dispostos em um espaço euclidiano/newtoniano estão completamente separados entre si: não há relação.

- Quando propõe o progressivo conhecimento de objetos simples e compostos, afirma a possível definição destes objetos como tais, definição esta que nada mais é do que uma simplificação de características nem sempre uniformes, imutáveis ou substanciais, como demonstra a microfísica em seus experimentos.

A crítica de Bachelard a Descartes nasce nesse sentido, já que, "[...] o método cartesiano que consegue explicar tão bem o mundo, não chega a complicar a experiência, o que é a verdadeira função da pesquisa objetiva" (1974, p.317). A posição simplista de Descartes diante do conhecimento posição esta que tanto influenciou a ciência moderna - é o objeto desta crítica.

Contra Descartes, Bachelard critica o cogito cartesiano, opondo-lhe um cogito complexo, hierarquizado em níveis; à matéria, entendida por Descartes como mera res extensa, absolutamente independente da consciência, Bachelard propõe o objeto que resulta de uma objetivação, expondo a estreita solidariedade entre sujeito e objeto na constituição da imagem do mundo (CÉSAR, 1996, p.101).

O que se percebe é, portanto, uma espécie de estagnação do processo de conhecimento - estagnação já dirigida por Bachelard às descobertas 
científicas irrisórias no âmbito dos métodos e epistemologias, durante muito tempo. Quando garantida a substancialidade do ato de conhecer através da noção de "eu existo", cessa a necessidade da busca de novos métodos de análise. Se o método prova de forma substancial a existência do agente do conhecimento, não são mais necessários métodos inovadores (CÉSAR, 1996, p.91).

Em decorrência das novas descobertas das ciências físicas, químicas e geométricas - sobretudo, no tocante aos novos métodos que possibilitaram tais descobertas - Bachelard (1974, p.318) põe em cheque o método de Descartes:

\begin{abstract}
Enquanto a ciência de inspiração cartesiana fazia com muita lógica o complexo com o simples, o pensamento científico contemporâneo tenta ler o complexo real sob a aparência simples oferecida por fenômenos compensados; esforça-se para encontrar o pluralismo sobre a identidade, para imaginar ocasiões para romper a identidade por detrás da experiência imediata resumida muito cedo num aspecto de conjunto.
\end{abstract}

Portanto, assim como em Kant, tendo em vista os avanços das ciências no tocante, principalmente, às noções de espaço e tempo, alguns quadros epistemológicos precisam ser revistos. Mais uma vez, evidencio a importância que Bachelard dá a uma nova percepção do processo do conhecimento, mais precisamente à noção de uma nova forma de crítica constituinte, complementar, alargadora de pressupostos epistemológicoaxiomáticos. Sua crítica a Descartes "não é sobre a condenação das teses físicas cartesianas, ou mesmo a condenação do mecanismo cujo espírito continuava cartesiano [...], mas sim sobre uma condenação da doutrina das naturezas simples e absolutas" (BACHELARD, 1974, p.317). Bachelard não pretende negar Descartes contrapondo-o aos novos métodos científicos: pretende, de alguma forma, complementá-lo, justapondo-o a esses novos métodos.

O ponto central deste trabalho situa-se, como já assinalei, em uma espécie de transfundo hermenêutico da obra de Bachelard, no sentido de ressignificação ou reestruturação de campos linguísticos e de sentido dos enunciados científicos e filosóficos. A necessidade de uma tal reestruturação advêm da própria necessidade de ruptura com os velhos axiomas. Para que se rompa com o antigo, inevitavelmente, se deve construir o novo. $\mathrm{O}$ novo começa a ser construído, primeiramente no campo dos métodos - com a complementação do antigo sistema ternário, tornando os métodos mais complexos e profundos do que uma intuição primeira que se fez base dos saberes por tanto tempo. Em um segundo momento, o novo nasce como produto linguístico e semântico destes novos métodos: a formulação do enunciado móvel (impermanente) de um novo sistema de pensamento. 
À reformulação que é proposta por Bachelard dá-se o nome de novo espirito científico (NEC) ${ }^{8}$. Faz-se importante a compreensão dos mecanismos desse novo espírito científico, para que assim se possa compreender um possível transfundo hermenêutico na obra de Bachelard. Boa parte destes mecanismos é estruturante das críticas ao antigo sistema ternário, ou seja, nos elementos de uma lógica não-aristotélica, de uma geometria não-euclidiana/newtoniana e de uma epistemologia nãocartesiana. $\mathrm{O}$ transfundo hermenêutico reside, justamente, no que se cria a partir de então, logo, advêm desta necessidade de ruptura. Logo, completa a própria ruptura em sentido criativo.

A linguagem dos novos axiomas se tornou muito menos simplista que a utilizada pelo antigo sistema ternário, no sentido de elevar ao máximo a percepção dos diversos elementos que passam a compor o axioma. Isso se torna bem claro analisar-se a crítica efetuada pela lógica não-aristotélica que expus anteriormente. Torna-se evidente também quando se tem uma noção mínima da complexidade dos resultados - sempre parciais - das ciências contemporâneas.

\begin{abstract}
Não se podem apresentar de uma só vez todas as consequências da filosofia quântica [por exemplo] porque ela é uma filosofia essencialmente composta. É muito difícil sobretudo considerar à primeira vista o caráter essencialmente pluralístico da nova estatística microfísica. Para conseguir isso, será preciso imaginar a pluralidade considerada como sendo anterior à unidade (BACHELARD, 2010, p.25).
\end{abstract}

Portanto, para a compreensão dos novos discursos é necessária, sobretudo, disposição, no sentido de uma análise mais completa possível das novas perspectivas apresentadas. Uma reformulação linguística e de sentido também pressupõe uma reformulação do espírito que anima o conhecedor: o NEC não está presente somente nos novos métodos de estudo, mas também se mostra como o combustível que alimenta o agente conhecedor.

Talvez o grande problema inerente ao NEC seja a necessária combinação entre a impermanência dos novos conhecimentos - já que, estes agora são vistos como conscientemente incompletos e parciais - e a permanência do significado das palavras. Como pode um conhecimento que se diz impermanente ser exposto através de uma linguagem estática?

Não existe nada de comum entre a permanência da significação de uma palavra e as permanências das propriedades de uma coisa. É preciso, pois, distinguir, entre o postulado tautológico que impõe a permanência da palavra e o postulado de identidade. $\mathrm{O}$ postulado de identidade impõe a permanência do objeto, ou, mais exatamente, a permanência de um caráter ou

\footnotetext{
${ }^{8}$ No decorrer de sua obra, Bachelard nomeia de diversas formas essa concepção do novo que advêm da ruptura. O novo espírito científico é sua forma mais geral.
} 
de um grupo de caracteres de um objeto (BACHELARD, 1974, p.228).

A base desta nova compreensão e enunciação situa-se principalmente em dois pontos: (1) em uma efetiva hermeneutização do caminho que vai da palavra ao objeto. Faz-se necessário que o agente do conhecimento tenha em vista que o preceito de identidade de um objeto de análise se dá somente através de uma perspectiva de aproximação. A descrição, enunciação, definição ou identificação deve ter em vista as nuances de uma identidade impermanente, não-substancial. A nova necessidade linguística advinda a partir do NEC é, justamente, conciliar a mutabilidade dos objetos - que não são mais considerados segundo uma definição clássica de "objeto" - com a aparente imutabilidade das palavras e de seus sentidos: "nunca se tem a garantia de ser examinado um objeto sob todos os aspectos; o postulado ultrapassa, pois, sempre a experiência. É na medida em que ultrapassa a experiência - tendo nascido na experiência - que ele é um postulado" (BACHELARD, 1974, 229).

Ao analisar-se e um sentido genealógico as novas estruturas linguísticas e de sentido advindas do NEC, inevitavelmente se recairá na própria reestruturação da aritmética. $\mathrm{O}$ fato de a lógica aristotélica ter dado à luz a um sistema de pensamento filosófico demasiadamente fechado, contribuiu, inevitavelmente para um progressivo fechamento das doutrinas aritméticas. $\mathrm{O}$ espectro produto de tal fechamento pode ser apontado como um dos principais responsáveis pela imutabilidade dos paradigmas científicos. Passo a uma breve exposição de um exemplo usado por Bachelard (2010, p. 60-62), no sentido de elucidar (2) a necessidade não só de uma ressignificação da palavra ao objeto, mas também do símbolo ao sentido - da fórmula aritmética ao seu possível produto.

A equação ${ }^{9}$ proposta pelo físico Willian Hamilton no sentido de calcular a energia de um sistema mecânico, que usa em sua constituição as coordenadas cartesianas, se apresenta sob a seguinte forma:

$$
\mathrm{H}(x, y, z, t, P x, P y, P z)=\mathrm{E}
$$

Ao ter-se em vista as teorias da mecânica ondulatória - mais propriamente as proposições do físico Erwin Schrödinger - a seguinte equação apresentarse-á sob a nova perspectiva:

$$
\mathrm{H}\left(x, y, z, t,-\frac{h}{2 \pi i} \frac{\delta}{\delta x},-\frac{h}{2 \pi i} \frac{\delta}{\delta y},-\frac{h}{2 \pi i} \frac{\delta}{\delta z}\right)=\mathrm{E}
$$

Onde as novas variáveis advêm de todos os microfenômenos renegados pela mecânica clássica. Em outras palavras, o que Schödinger faz é tornar a visão de Hamilton mais completa e complexa, de acordo com o NEC. A abertura

\footnotetext{
${ }^{9}$ Não é minha intenção - assim como não foi a de Bachelard - analisar a equação em si e seus possíveis resultados. Apresento tal exemplo, para elucidar mais claramente os diversos vieses em que uma reestruturação dos sentidos simbólicos se faz necessária a partir dos novos paradigmas científicos.
} 
linguística e de sentido se estende assim ao domínio aritmético. Assim, a organização dos símbolos ganha seus novos sentidos, sempre provisórios e inacabados.

Este transfundo hermenêutico inerente a percepção de Bachelard acerca dos novos enunciados científicos é mais bem compreendido ao ter-se em vista ainda dois outros elementos constituintes, basilares: 1- A posição do filósofo diante destes novos saberes científicos; 2- O domínio de uma nova forma de dialética que advêm, justamente, das novas possibilidades epistemológicas e metodológicas.

É tema recorrente na Tradição a intersecção ou separação necessária que se dá - ou não - entre os saberes científicos e filosóficos. Bachelard (1974, p.249), como se pode deduzir, dá certa centralidade à questão de uma filosofia da ciência comparada a outras formas do saber filosófico: "cedo ou tarde é a filosofia científica que se tornará o temo fundamental da polêmica filosófica; tal pensamento levará a substituir as metafísicas intuitivas e imediatas pelas metafísicas discursivas objetivamente retificadas". Ou seja, através dos novos paradigmas científicos é que a filosofia tende a se reformular. Em alguns momentos o autor é categórico. Como quando ao afirmar que "a ciência cria, com efeito, uma filosofia" (BACHELARD, 1974, p.250). Dentro desta perspectiva de criação de uma filosofia através da ciência,

\footnotetext{
o filósofo deve [...] tornar flexível sua linguagem para traduzir o pensamento contemporâneo em sua versatilidade e mobilidade. Deve também respeitar a estranha ambiguidade que pretende que seja todo pensamento científico interpretado ao mesmo tempo na linguagem realista e na linguagem racionalista (Ibidem).
}

O domínio do NEC são se dá somente no sentido da possível retificação dos paradigmas científicos, mas também - como sugere o termo cunhado acima - em um domínio de reformulação, tradução linguística e semântica do discurso da ciência, tendo em vista a sua absorção no discurso filosófico: logo, o domínio do NEC é hermenêutico. As novas formas de percepção do mundo necessitam igualmente de uma nova forma de enunciação destas experiências, "não se trata de fazer historiografia da ciência, mas de, acompanhando a ciência contemporânea, na sua constante atualização, procurar suas bases filosóficas" (CÉSAR, 1996, p.38).

Portanto, o filósofo é aquele que sistematiza e traduz a linguagem científica para um âmbito filosófico, sem necessariamente excluir o princípio da criação, já que, também cabe ao seu papel se apropriar destes novos conhecimentos e determinar as "novas estruturas espirituais", estabelecendo assim os princípios de uma "nova pedagogia" (BACHELARD, 1974, p.235). O filósofo da ciência é, acima de qualquer coisa, um hermeneuta que direciona seus esforços tanto na tradução quanto 
na criação das bases linguísticas e de sentido que darão suporte a esta nova pedagogia, que nega, por sua vez, as conclusões simplistas das impressões primeiras. O filósofo, assim como o próprio cientista, é um criador.

O filósofo que quer aprender o ultrarracionalismo não deve, pois, instalar-se de uma só vez no ultrarracionalismo. Deve experimentar as aberturas do racionalismo umas após outras. Deve procurar um a um os axiomas a dialetizar. Um só axioma dialetizado basta para fazer cantar toda a natureza BACHELARD, 1974, p.242).

Ultrarracionalismo a que se refere Bachelard seria uma nova tendência racional advinda do NEC. Portanto, a dialetização dos conceitos é o elemento central que faz do filósofo um criador e experimentador destas novas concepções de realidade.

A dialetização dos antigos conceitos advindos de uma lógica generalista e fechada, praticamente se confunde com este horizonte hermenêutico que proponho inerente às sintetizações de Bachelard acerca das novas ciências. Logo, diz respeito à atuação do filósofo como hermeneuta.

\footnotetext{
Mas não se é filósofo se não se tomar consciência, num determinado momento da reflexão, da coerência e da unidade do pensamento, se não se formularem as condições de síntese do saber. E é sempre em função desta unidade, desta coerência, desta síntese, que o filósofo coloca o problema geral do conhecimento (BACHELARD, 1974, p.162).
}

Este formular "as condições de síntese do saber", se daria, portanto, dentro de uma conjuntura hermenêutica, onde o cientista e o filósofo fariam rodar a roda dos sentidos.

Porém, é preciso se ter em mente, sobretudo, que a noção de dialética apresentada por Bachelard, não condiz estruturalmente com a dialética defendida por boa parte da Tradição. Retomando as palavras do físico C. Bialobrzeski, Bachelard (1974, p.240) procura elucidar sobre uma necessária renovação do conceito de dialética, no sentido de construir as bases metodológicas do NEC. Dentro desta perspectiva, se opõe à dialética hegeliana, por exemplo, na medida em que a concepção dialética de Hegel contrapõe tese à antítese, esperando, em um terceiro momento, através da fusão destes dois elementos necessariamente contraditórios, o aparecimento da síntese, que representaria, por sua vez, o novo. Nesta noção dialética, o novo advém da contraposição racional e um tanto simplista dos conceitos contraditórios. A física newtoniana trabalha dentro desta conjuntura que, naturalmente, nasce muito antes da filosofia de Hegel - este é apontado como herdeiro moderno de tal ideal, sendo que, a racionalidade inerente a esta dialética, vem ao mundo contemporâneo através do marxismo. 
A dialética defendida por Bialobrzeski e, consequentemente, por Bachelard, diz muito mais respeito à justaposição do que à contraposição. Em trecho citado por Bachelard (Ibidem), Bialobrzeski atenta para a existência de "uma certa semelhança entre as noções físicas [contemporâneas] e o método sintético de Octave Hamelin, no qual a antítese não é uma negação da tese: as duas noções que se combinam numa síntese (hameliana) são opostas mas não são contraditórias". Quando retomada a crítica bachelardiana à racionalidade aristotélica, tal preceito de justaposição se torna ainda mais claro como uma espécie de abertura dos axiomas: nesse sentido, a dialetização dos conceitos se apresenta como uma espécie de expansão dos núcleos de sentido possíveis. Se antes o elétron só poderia ser visto como um corpúsculo, agora o elétron pode ser visto tanto como corpúsculo ou como fenômeno ondulatório - ou seja, dois enunciados físico-filosóficos aparentemente opostos, mas que pertencem ao mesmo "objeto", logo, não contraditórios. A contradição deixa de ser o princípio animador da mudança: a justaposição dos conceitos, sua dialetização ou complicação é quem agora anima o sistema. Dentro desta perspectiva de justaposição "pensar corretamente o real, é aproveitar as suas ambiguidades para modificar e alterar o pensamento. Dialetizar o pensamento é aumentar a garantia de criar cientificamente fenômenos completos [...]" (BACHELARD, 1974, p.168).

No decorrer desta breve exposição, além de recapitular de forma introdutória parte do percurso filosófico de Gaston Bachelard, tentei atentar de forma experimental a um possível transfundo hermenêutico inerente à sua obra, no que diz respeito às suas percepções acerca dos novos métodos das ciências naturais, mais precisamente, das novas noções de tempo, espaço e irradiação de energia (física relativista, quântica e ondulatória). Este trabalho também nasce dentro de uma perspectiva de apontar para futuras pesquisas tendo como objeto esta nova racionalidade cada vez mais latente e necessária, muito bem sintetizada nas obras de Bachelard.

Intrínseco às exposições que apresentei aqui, também pode se encontrar uma possível expansão do próprio método da hermenêutica, na medida em que deixo de percebê-la unicamente segundo sua tradição clássica de análise. A hermenêutica em Bachelard partiria dos enunciados científicos, para daí retirar - textualmente, inclusive - novas significações do real, novos proposições de mundo. Muito mais que hermenêutica da tradição filosófica, Bachelard faz uma hermenêutica dos axiomas científicos.

$\mathrm{Na}$ medida em que percebo Bachelard como hermeneuta, acredito entrar em consonância com algumas pesquisas que o pintam como construtor de uma nova epistéme em Filosofia. Uma análise breve às obras de Foucault e Bourdieu, por exemplo, de certa forma elucidam uma nova forma de fazer Filosofia, forma esta um tanto mais complexa de compreender de maneira efetiva, mas que parece analisar muito mais fatores 
do que a Filosofia Clássica e Moderna, na mesma medida em que parece conversar muito mais de perto não só com as novas formas de concepções de mundo advindas das ciências, mas também com formas inovadoras de metodologia. Um Bachelard hermeneuta nasceria, justamente, como aquele que abre caminho para uma nova percepção e que coloca como centro desta abertura o cientista, o filósofo e inclusive o poeta que inova metodológica e epistemologicamente.

\section{Referências bibliográficas:}

ARISTÓTELES. Órganon. São Paulo: Edipro, 2010.

BARBOSA, Elyana. "Espaço-tempo e poder-saber. Uma nova epistéme? (Foucault e Bachelard)". Tempo Social; Revista Sociol. USP, São Paulo, n.7 (1-2), pp.111-120, out. 1995.

BACHELARD, G. A Experiência do Espaço na Física Contemporânea. Rio de Janeiro: Contraponto, 2010.

A Filosofia do Não: Filosofia do Novo Espírito

Científico. In: Os Pensadores. São Paulo: Abril Cultural, 1974. pp. 159-245. . A Poética do Espaço. In: Os Pensadores. São Paulo: Abril Cultural, 1974. pp. 339-512. . O Novo Espírito Científico. In: Os Pensadores. São Paulo: Abril Cultural, 1974. pp. 247-338.

BROGLIE, Louis de. Ondas, Corpúsculos y Mecánica Ondulatoria. Buenos Aires: Espasa-Calpe, 1949.

CÉSAR, Constança Marcondes. A Hermenêutica Francesa: Bachelard. São Paulo: Alínea, 1996.

DESCARTES, René. Discurso do Método. Porto Alegre: L\&PM, 2005.

DUQUESNE, Maurice. Matéria e Antimatéria. São Paulo: Difusão Europeia do Livro, 1961.

EINSTEIN, Albert. "A Influência de Maxwell Sobre a Evolução da Realidade Física". In: Como Eu Vejo O Mundo. Rio de Janeiro: Editora Nova Fronteira, 1981. pp. 192-198.

. A Teoria da Relatividade Especial e Geral. Rio de Janeiro: Contraponto, 2000.

LANDAU, Lev Davidovich; RUMER, IUriĭ Borisovich. O Que É a Teoria da Relatividade. Moscou: Editora Myr, 1986.

RUSSELL, Bertrand. ABC Da Relatividade. Mira-Sintra: Publicações Europa-América, 1974. 